\title{
BMJ Open Link between COVID-19-related in- hospital mortality in continental France administrative areas and weather: an ecological study
}

\author{
Mehdi Mejdoubi (D , ${ }^{1}$ Mehdi Djennaoui, ${ }^{2}$ Xavier Kyndt ${ }^{2}$
}

To cite: Mejdoubi M, Djennaoui M, Kyndt X. Link between COVID-19-related inhospital mortality in continental France administrative areas and weather: an ecological study. BMJ Open 2021;11:e043269. doi:10.1136/ bmjopen-2020-043269

- Prepublication history and additional material for this paper is available online. To view these files, please visit the journal online (http://dx.doi.org/10. 1136/bmjopen-2020-043269).

Received 30 July 2020

Revised 15 February 2021

Accepted 25 February 2021

\section{Check for updates}

(c) Author(s) (or their employer(s)) 2021. Re-use permitted under CC BY-NC. No commercial re-use. See rights and permissions. Published by BMJ.

${ }^{1}$ Department of Radiology, Hospital of Valenciennes, Centre Hospitalier de Valenciennes, Valenciennes, Hauts-de-France, France

${ }^{2}$ Department of Public Health, Hospital of Valenciennes, Hospital Centre Valenciennes, Valenciennes, Hauts-de-France, France

Correspondence to Professor Mehdi Mejdoubi; mejdoubi-m@ch-valenciennes.fr

\section{ABSTRACT}

Objective To assess the effect of a weather index on inhospital COVID-19-linked deaths.

Design Ecological study.

Setting Continental France administrative areas (départements; henceforth counties). The study period, from 18 March to 30 May 2020, corresponds to the main first outbreak period in France.

Population COVID-19-linked in-hospital deaths. Main outcome measures In-hospital deaths and demographics (population, human density, male sex and population percentage $>59$ years old) were obtained from national and centralised public databases. County weather indexes were calculated by the French National Meteorological Agency.

Methods In this observational ecological study, the relationship between in-hospital COVID-19-related mortality and climate zones in continental French counties were analysed, by comparing the cumulative in-hospital death tolls in France by county to other factors (population density, climate, age and sex). The study period lasted from 18 March to 30 May 2020. A multivariate linearregression analysis of in-hospital mortality included climate zones, population density, population $>59$ years old and percentages of males as potential predictors. The significance level was set at $5 \%$.

Results Weather indicators and population density were factors independently associated with the COVID-19 death toll. Colder counties had significantly higher mortality rates $(p<0.00001)$. Percentages of males and population $>59$ years old in counties did not affect COVID-19 in-hospital mortality.

Conclusions Many parameters influence COVID-19 outbreak-severity indicators. Population density is a strong factor but its exact importance is difficult to discern. Weather (mainly cold winter temperatures) was independently associated with mortality and could help explain outbreak dynamics, which began and were initially more severe in the coldest counties of continental France. Weather partly explains fatality-rate discrepancies observed worldwide.

\section{INTRODUCTION}

The world is experiencing a major novel COVID-19 pandemic since December 2019, with $>1570000$ deaths (as of 10 December

\section{Strengths and limitations of this study}

- This ecological study is based on a country with data reliability, different climate zones and homogeneous social conduct during the study period.

- French continental administrative areas include coastal, non-coastal and other counties with cold winters.

- Generalisability of our results is mainly valid for temperate climates.

- Due to the ecological design of the study, we were unable to control for co-morbidities in the multivariate analysis.

2020). ${ }^{1}$ In France, the outbreak began in early March 2020 in the Alsace 'Département' (an administrative area comparable to a county in the USA and UK; henceforth county), quickly spread throughout continental France, with the major hotspot being Paris and its suburbs. ${ }^{2}$ The national lockdown, started 17 March 2020, achieved flattening of the infection-outbreak curve (with the mortality peak reached on 6 April) and was eased on 11 May 2020. ${ }^{2}$ Deaths exceeded 30000 during the first wave and, although the outbreak seemed to be under control during the summer, a second wave started in October 2020.

SARS-CoV-2 transmission causes COVID19. All epidemics are the result of multiple factors, like population density, human displacements and individual human susceptibility (age, comorbidities, etc). The question remains whether meteorological parameters are an independent factor of disease transmission and/or severity. Epidemiological studies are often biased by the imprecise results of large-scale biological testing, which has only recently been fully implemented in France. In-hospital deaths are a more reliable data source, even though it encompasses different 
types of patients (some intensively treated, other just receiving palliative care).

This study was undertaken to explore the relationship between COVID-19-linked in-hospital deaths, at the county level and weather indicators.

\section{METHODS}

\section{Population}

In this observational ecological study, the relationship between in-hospital, COVID-19-linked mortality and climate zones in 94 continental French counties areas was analysed. The overseas territories and Corsica were excluded from the analysis because of their particular localisations (with tropical or subtropical climate for some) and special insular conditions (for some). The study period lasted from 18 March to 30 May 2020.

\section{Data}

We compared the cumulative in-hospital death tolls in continental France (64million inhabitants) by county to other factors (population density, climate, age and sex). The 18314 deaths in France during the observation period classified by county were obtained from the French open-source database (Santé Publique France). ${ }^{3}$ On 31 May and throughout June 2020, respectively, 35 and 888 additional in-hospital deaths were not considered for the study. In France, access to healthcare is free and during this outbreak, there was no shortage of available conventional or ICU hospital beds. In-hospital deaths in France are assigned to the areas where the deceased persons lived.

The following demographic characteristics for each county were obtained from the French Institute for Statistics and Epidemiology (INSEE) ${ }^{4}$ : total population, percentage of the population $>59$ years (INSEE categorises oldest populations in only two classes: $60-74$ and $\geq 75$ years old), percentage of males in the population and human density per $\mathrm{km}^{2}$.

To assess the climate conditions, the French counties were classified according to a French Climate Severity Index (Indice de Rigueur Climatique). ${ }^{5}$ That Index is calculated (from local measurements in each zone) by the French National Meteorological Agency. Three main climate patterns (H1, H2, H3; figure 1) are defined according to winter temperatures, with $\mathrm{H} 1$ representing the coldest zone and H3 the warmest. Regional H2 zones are known to be homogeneous, which contrasts with $\mathrm{H} 1$ zones, sub-characterised according to summer temperatures and coastal influence into H1a, H1b, H1c (with H1b being colder in winter and hotter in summer than H1a). These zones are ranked according to winter temperatures from coldest to warmest: $\mathrm{H} 1 \mathrm{~b}>\mathrm{H} 1 \mathrm{a}>\mathrm{H} 1 \mathrm{c}>\mathrm{H} 2>\mathrm{H} 3$. The data used were collected historically and are not from winter 2020.

\section{Patient and public involvement}

No patients were directly involved in this study.

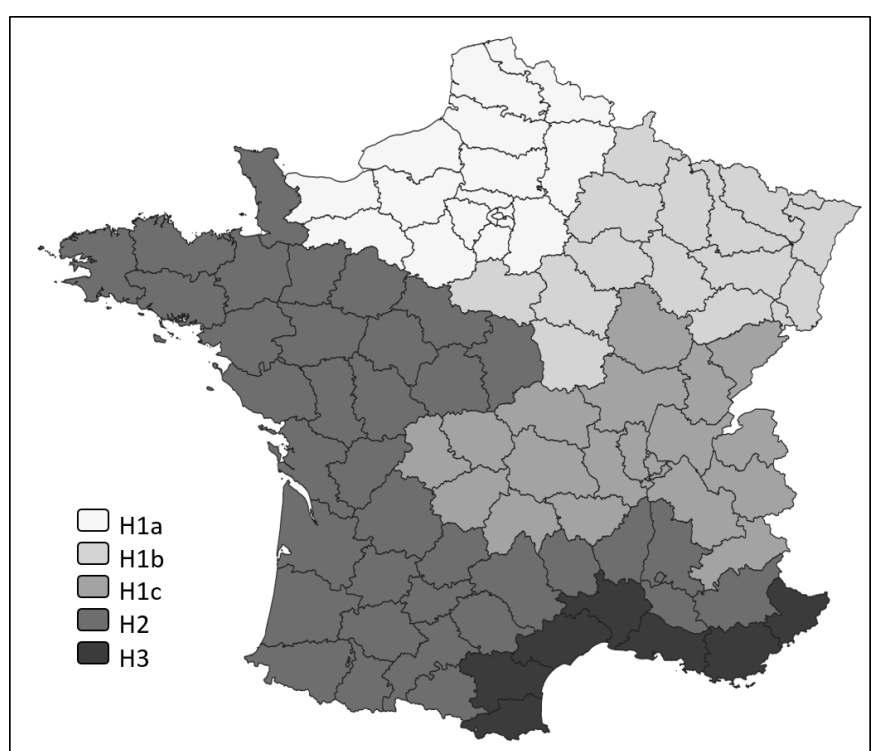

Figure 1 Main climate zones $(\mathrm{H} 1 \mathrm{a}, \mathrm{H} 1 \mathrm{~b}, \mathrm{H} 1 \mathrm{c}, \mathrm{H} 2, \mathrm{H} 3)$ of continental France counties ('départements').

\section{Statistical analyses}

All database variables were tested. Bivariate analyses were computed between in-hospital COVID-19-related mortality, and each weather indicator and each demographic parameter (density, age, sex). For comparisons, the Kruskal-Wallis test and Pearson's correlation test were used, as appropriate. The significance level was set at $5 \%$. Those bivariate analyses were also completed by multivariate linear-regression analysis (first multivariate model). The statistical quality of the model was assessed with the variance-covariance matrix of residuals and normality for their distribution. Data were analysed by Cook's distance, which showed three counties with outliers: Paris (which received patients from its suburbs because, as the nation's capital, it has a disproportionately higher hospital density), Haut-Rhin and Belfort (eastern France, where the outbreak began). Therefore, a second multivariate model excluding outliers was built, which had a more homogeneous distribution of residuals. The multivariate analysis was finalised by a multiple linear-regression model excluding outliers, with categorisation of quantitative data into binary variables using the third quartile as the threshold value (third model). The statistical analyses were computed with R software V4.0.0.

\section{RESULTS}

Demographic and hospital data characteristics during the study period are reported in table 1 .

Bivariate analysis demonstrated a significant link between in-hospital COVID-19-related mortality and climate zone (figure 2A). Mean (SD) mortality rates for climate zones H1a (table 2), H1b, H1c, H2 and H3 differed significantly $\left(\mathrm{p}=8.84 \times 10^{-10}\right)$.

Bivariate analysis (correlation coefficients) also found significant independent statistical links between 
Table 1 French county demographic and COVID-19-linked mortality data

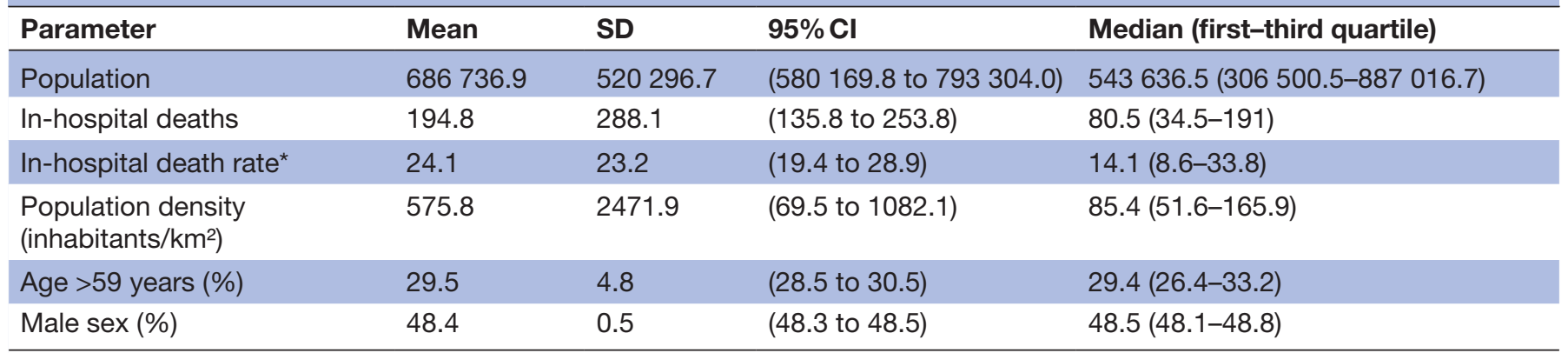

*Number per 100000 inhabitants.

COVID-19-related mortality and population density or age $>59$ years but not male sex (table 3 ).

According to multivariate analysis of the initial data (using zone $\mathrm{H} 2$ as the reference), COVID-19-linked mortality was associated with the following parameters: climate zones H1a (regression coefficient 14.6, $\mathrm{p}=0.00962$ ) and H1b (regression coefficient 37.2, $\mathrm{p}=4.39 \times 10^{-11}$ ), population density (regression coefficient $0.003, p=0.000229$ ) and age (regression coefficient -0.97 , $\mathrm{p}=0.0208$ ) (online supplemental appendix 1). Results of the multiple linear-regression model excluding outliers (Cook's distance $>0.1$ ) were similar, with statistically significant effects for climate zones H1a (regression coefficient 15.2, $\mathrm{p}=0.000785$ ) and H1b (regression coefficient $30.4, \mathrm{p}=7.65 \times 10^{-11}$ ), population density (regression coefficient $0.004, \mathrm{p}=0.00028$ ) and age (regression coefficient $-0.6, \mathrm{p}=0.0404$ ) (online supplemental appendix 2). Residual analyses for the multivariate models using the initial data was less conclusive than that excluding outliers. After categorisation of quantitative data into binary variables, results remained similar with statistically significant effects of climate zones $\mathrm{H} 1 \mathrm{a}$ and $\mathrm{H} 1 \mathrm{~b}$ and population density (table 3) (figure 2B). The only difference between the third model and the second model was the non-significance of the age. H3 climate zone and male sex were not significant in any of the three models constructed.

\section{DISCUSSION}

Our results showed that COVID-19-related in-hospital mortality-throughout continental France-was due to at least two independent factors: weather index and population density. We did not find a difference among counties for the percent population aged $>59$ years or male sex. As for any outbreak, the COVID-19 pandemic has multifactorial origins. Some are already well-documented: individual factors (age, male sex, comorbidities), high population density and all types of human displacements. Many others are still being discussed (weather indicators, socio-economic factors, immune status).

Individual risk factors for COVID-19 severity were identified relatively quickly, as this pathology often requires hospitalisation (with or without ventilation), and it first emerged in developed countries, after Wuhan, China. The main severity factors reported are: age $>50$ years,
A

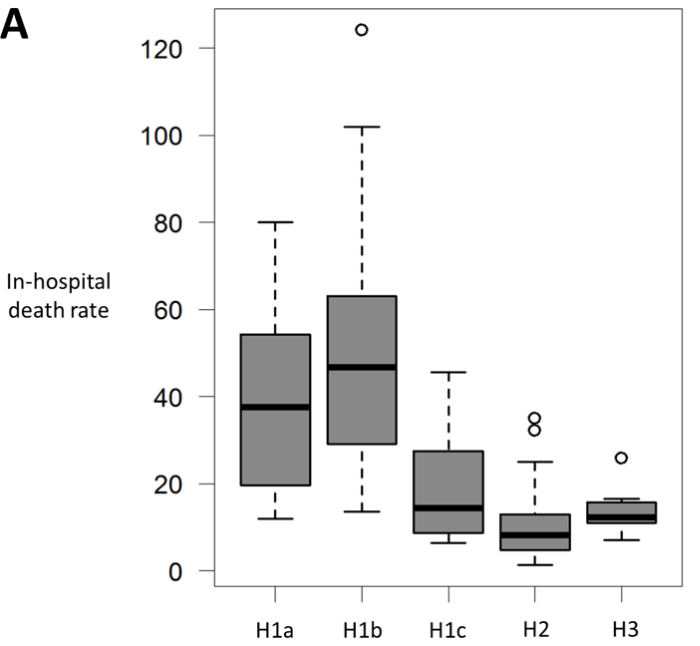

B

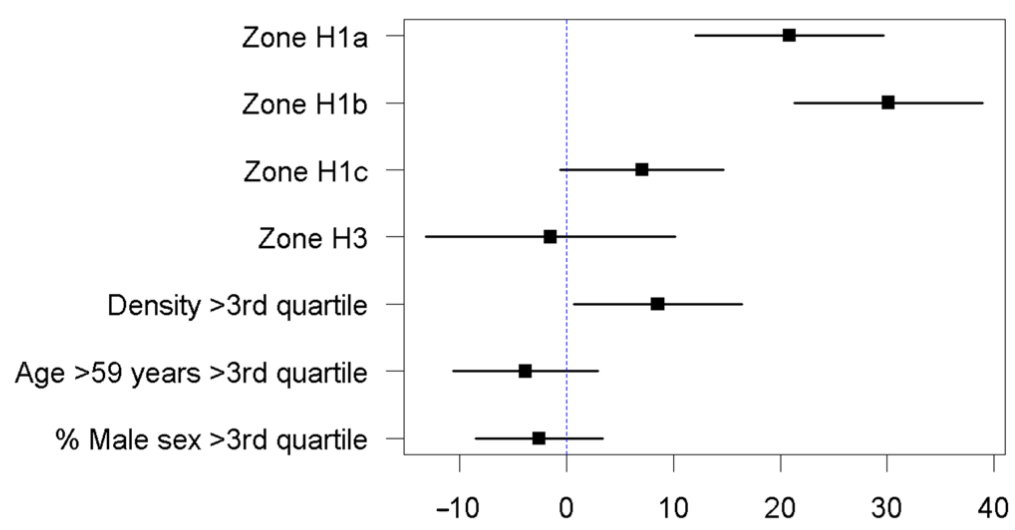

Figure 2 (A) Boxplots of in-hospital mortality rates according to the main climate zones. The internal bold horizontal line is the median; the lower and upper box limits are the first and third quartile, respectively; and the T-bars represent range. (B) Multivariate linear-regression analysis ( $95 \% \mathrm{Cls}$; with $\mathrm{H} 2$ serving as the reference). The analysis retained climate zones ( $\mathrm{H} 1 \mathrm{a}$, $\mathrm{H} 1 \mathrm{~b})$ and population density as independent factors significantly influencing in-hospital mortality. 
Table 2 French demographic and COVID-19-linked mortality data according to climate zone

\begin{tabular}{llllllll}
\hline Climate zone & $\begin{array}{l}\text { Counties, no. Population, } \\
\text { (\%) }\end{array}$ & mean & $\begin{array}{l}\text { Population, } \\
\text { density mean* }\end{array}$ & $\begin{array}{l}\text { Age } \\
\text { >59years } \\
\text { mean (\%) }\end{array}$ & $\begin{array}{l}\text { Male sex, } \\
\text { mean (\%) }\end{array}$ & $\begin{array}{l}\text { In-hospital } \\
\text { means, }\end{array}$ & $\begin{array}{l}\text { In-hospital } \\
\text { death rate†, } \\
\text { mean (SD) }\end{array}$ \\
\hline H1a & $18(19)$ & 1193507.1 & 2583.9 & 24.1 & 48.4 & 517.3 & $39.2(21.8)$ \\
H1b & $15(16)$ & 473311.2 & 100.8 & 29.4 & 48.7 & 258.3 & $51.2(31.4)$ \\
H1C & $18(19)$ & 551782.5 & 105.1 & 30.1 & 48.5 & 120.5 & $18.3(11.8)$ \\
H2 & $36(38)$ & 529843.7 & 80.4 & 31.6 & 48.4 & 50.6 & $10.2(8.2)$ \\
H3 & $7(7)$ & 994859.8 & 187.6 & 31.0 & 47.7 & 161.7 & $14.0(6.0)$ \\
\hline
\end{tabular}

${ }^{*}$ Inhabitants/land area.

†Number per 100000 inhabitants.

comorbidities, male sex..$^{6-8}$ Comorbidities are independent factors with a multivariable OR ranging from 1.31 (diabetes) to 2.94 (pulmonary disease). ${ }^{6}$ Age is a major independent factor, with a reported multivariable OR of 1.10 per 1-year increment ${ }^{7}$ or 1.31 per 10 -year increment ${ }^{6}$ and male sex has an OR of 1.13. We attribute our inability to find an age effect among French counties to: first, only in-hospital deaths were available according to county and, second, the oldest patients were not systematically hospitalised (while in-assisted-residence deaths accounted for one-third of the death toll in France). Therefore, the among-county differences for those $>59$-year-old class deaths were not retrieved from the in-hospital death data.
Nevertheless, despite the significantly higher proportion of >59-year olds in H1c, H2 and H3 climate zones (table 2), in-hospital mortality was significantly higher in H1a zones.

We did not find male sex to be discriminant among French counties, because they had a mean $48.4 \%$ of males with a small SD of 0.5. Ethnicity ${ }^{9}$ and socio-economic status have also been evoked as etiological factors but their independence remains to be proven.

For most epidemics, especially of respiratory diseases, population density is a major cause of transmission. Cities are more affected than rural areas and, within cities, neighbourhoods with dense housing are, unsurprisingly,

Table 3 Bivariate and multivariate analyses of in-hospital death rates*

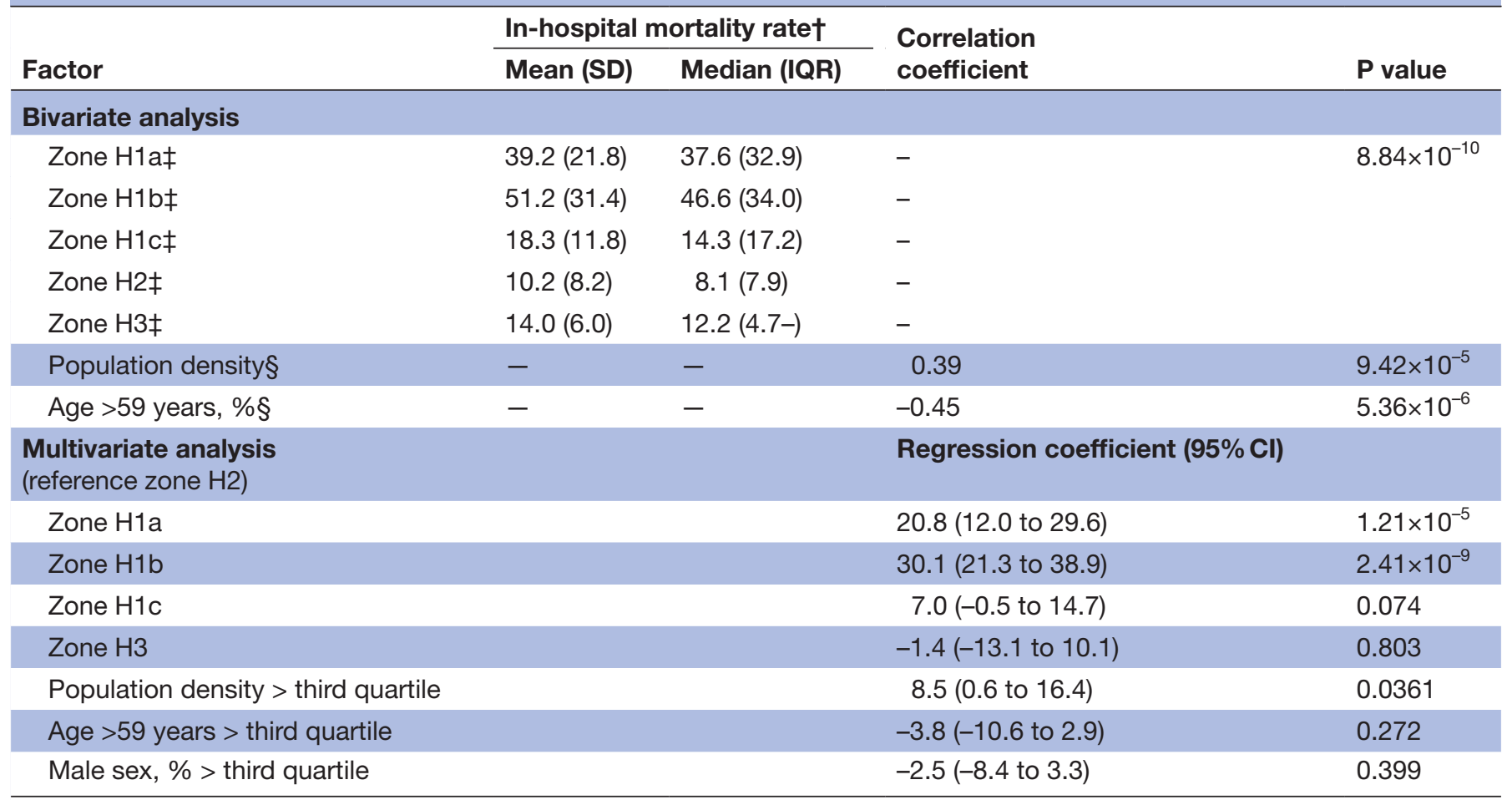

IQR (third - first quartile).

${ }^{*}$ Multiple-linear regression excluding outliers with categorised quantitative data.

†Number per 100000 inhabitants.

$\ddagger$ Łruskall-Wallis test.

$\S$ Pearson's correlation test. 
more affected. The highest death tolls were in big cities (New York, Paris, Madrid, London) and within them, poor neighbourhoods were more severely affected for highly interwoven reasons. However, the 'number of people/ land area' is a poor indicator of the human populationdensity characteristic, as it is embedded in a wide variety of situations (housing mode, transportation mode, innercity density, human interactions, cultural and behavioural habits). Indeed, many outbreaks occurred on (cruise or military) ships, ${ }^{10}$ likely due to the same combined effect of closed environment and prolonged contact. Thus, the Diamond Princess cruise was classified among the most affected 'entities' at the beginning of the pandemic in March 2020. ${ }^{11}$ That said, cruise ships are the perfect laboratory model of outbreak spread in small cities.

Our results showed human density to be an independent factor for COVID-19-related deaths but we acknowledge that its exact importance cannot be determined, as we are limited by the wide range of situations that human density encompasses, with many factors that should be taken into account. Our assessment of human density (and interactions) was mainly made during a lockdown; therefore, the importance of this factor is likely underestimated herein. Also, population density does not have the same connotation and consequences in poor and rich countries. The outbreak extension to hot climates indicates that human interactions are likely even more important for virus spread than weather (unlike our results).

The cities gather not only locals but also draws infected people, with airport arrivals representing the fastest entry point of the outbreak. Since the 1968-69 influenza pandemic, we have known that international travel and plane transportation is a major vector of virus displacement. According to Liu et al, ${ }^{12}$ COVID-19 has spread in multiple major cities in China that have large numbers of inbound and outbound passengers. They used an internet-based ('Baidu') Migration Scale Index for 30 cities and found an association with confirmed cases. Pertinently, population migration and displacement or movement-control measures implemented (quarantine, limited migration/limited travel/travel bans, closed borders) reduced virus spread everywhere. In 2019, the top five countries receiving international tourists were France, Spain, Italy, China and the USA. Those countries were the main ones affected by the pandemic during March and April 2020. This human migration dynamic partly explains the epidemic's temporality worldwide. ${ }^{13}$

Some human behaviours (hand shaking, cheek-kissing, body contact, crowds), intrinsically responsible for social distancing differences, are also likely to influence SARS-CoV-2 transmission. But, within a small-sized or medium-sized country (as in France), they may be relatively homogeneous. It is difficult to individualise these cultural factors, and no clear and unbiased study indicators have been identified, but they likely account for mortality discrepancies among countries. For example, massive virus spreading was reported after carnivals in different settings (New Orleans, Louisiana and Gangelt, Germany $^{14}$ ).

Viral epidemics, such influenza and gastroenteritis, are known to follow seasonal cycles with resurgences during autumn and winter, favoured by cold temperatures. Previous coronavirus outbreaks (SARS-CoV-1 and Middle East respiratory syndrome) were also linked to weather ${ }^{12}$ (mainly temperature). A climate effect on the wide dissemination of a respiratory disease is a highly intuitive conclusion and SARS-CoV-2 is transmitted mainly through droplets and aerosols. Temperature, humidity and wind were found to impact the spread of this outbreak, ${ }^{12}$ 15-19 based on confirmed infections. Notably, biological testing is known to monitor imprecisely this outbreak because $23 \%-40 \%$ of the cases are asymptomatic. $^{20}$ Moreover, false-negative reverse transcriptasepolymerase chain reaction results may occur. Therefore, our study focused on more precise, in-hospital deaths, collected in a centralised electronic database.

In many countries spanning multiple latitudes, clear north-south gradients ${ }^{18} 19$ were observed with more deaths further north: France, Spain, Italy, USA (as of 10 December 2020, New York State had more deaths (35 183) than Florida (19 462), ${ }^{1}$ despite Florida having a larger population and the highest percentage population in the USA >65 years old). Notably, Rome, the largest Italian city with a Mediterranean climate, was proportionally less affected than northern cities ${ }^{19}$ which have a different climate.

Based on our results for continental France, southern and coastal areas seem to be more protected than colder inland areas. Notably, our findings were confirmed by observations made in Spain, where the Madrid region was hit harder than coastal and southern zones. Western Europe (France, UK, Belgium, Netherlands and Germany) has a mainly oceanic climate and the outbreak followed the same course (sudden rise in March, decline in May and resumption in October 2020), ${ }^{1}$ despite their different public health-policy approaches. Also, few large cities in East and Southeast Asia (except Wuhan) were COVID-19 pandemic hotspots, despite human population density being among the highest in the world. That observation can be explained by: (1) aggressive management of the epidemic in cold areas (South Korea, Japan and China, which implemented the strictest lockdown in the world); (2) other protective behaviours, including traditional cultural distancing; (3) some protective climate effect in warm areas (Hong Kong, Singapore, Taiwan). Of course, the combination of these three factors would achieve the highest protection.

Pertinently, the climate's protective effect alone would not spare a population from the outbreak and, indeed, almost all countries on earth have been impacted. Moreover, the protection afforded by higher temperatures remains to be precisely defined depending on the climate, because the interactions among temperature, humidity, wind and sunlight are complex. Still, Prata et $a l^{21}$ showed that, in Brazil, the climate's effect may exist, 
even in tropical regions, where the range of temperatures is limited. Inversely, the results of Hallal et $a l \mathrm{~s}^{22}$ nationwide antibody-prevalence survey in Brazil showed that the most affected areas were located along the Amazon river, which has the warmest climate. They explained those findings by human density on boats, the major means of transporting people, and excess multifactorial risks among indigenous populations.

Air pollution also was shown to be associated with virus spread in northern Italy, ${ }^{23}$ but because pollution is closely related to weather conditions, its independent role remains to be specified.

Public health strategies have been extensively implemented worldwide. ${ }^{24}$ It is likely that climate alone is not sufficient to extinguish this outbreak, and public health interventions, aimed at containing and reducing virus circulation, will be needed on a long-term basis. Weather factors and human social behaviours (partly linked to meteorological conditions) seem to contribute to COVID-19 epidemiological dynamics. This multifactorial character could explain why, despite some climate protection, some warm areas in Central and South America are experiencing massive epidemics. Notably, their national strategies implemented only partial social distancing and, even now, persist in opposing it (Brazil, ${ }^{22}$ Mexico). Liu et $a l^{12}$ concluded rightly for China: 'this epidemic will be faded to a large degree in the coming warmer season with the enforcement of public health interventions in China,' which emphasises the absolute need for social distancing and not to rely solely on a weather effect.

\section{Strengths and limitations}

Few countries have simultaneous hospital data reliability, different climate zones, homogeneous social behaviour during the outbreak (including a uniformly implemented lockdown) and high COVID-19-related mortality. France met all those conditions. However, our study has some limitations. First, the death-toll breakdown per county is available only for in-hospital deaths. Second, the impact of each etiological factor may vary among different countries and climates, therefore, generalisability of our results is mainly valid for temperate countries in the northern hemisphere. Third, the France weather index we used provided a historic collection of weather data, but not winter 2019-2020 conditions. Finally, comorbidities could not be analysed because of the ecological design of the study but we think that their distribution is relatively homogeneous among French counties.

\section{CONCLUSION}

Our findings suggest that climate is an independent factor influencing COVID-19-linked mortality at the county level in continental France. Human population density (and therefore social interactions) is an independent factor, whose impact has been widely proven. These factors, along with others (age pyramid, cultural factors, comorbidities), explain the course of this pandemic throughout the world. The fatality discrepancies among countries and among administrative subdivisions within countries likely follow the same rules worldwide. Our findings also imply that this COVID-19 outbreak will last throughout the coldest periods, but seasonality is complex, as it involves more than climate alone (eg, immune status, virus mutation).

Contributors MM: conceptualisation, methodology, data curation, writing original draft. XK: methodology, writing, manuscript editing. MD: methodology, software, data curation, writing, manuscript editing. All authors have read and approved the submission.

Funding The authors have not declared a specific grant for this research from any funding agency in the public, commercial or not-for-profit sectors.

Map disclaimer The depiction of boundaries on this map does not imply the expression of any opinion whatsoever on the part of BMJ (or any member of its group) concerning the legal status of any country, territory, jurisdiction or area or of its authorities. This map is provided without any warranty of any kind, either express or implied.

Competing interests None declared.

Patient consent for publication Not required.

Provenance and peer review Not commissioned; externally peer reviewed.

Data availability statement Data are available in a public, open access repository. All data are public1.https://geodes.santepubliquefrance.fr/\#c=indicator\&i=covid_ hospit_incid.incid_dc\&s=2020-04-06\&t=a01\&view=map22. https://www.insee. fr/fr/statistiques/18931983.https://www.legifrance.gouv.fr/affichTexteArticle.do; jsessionid=C15D8E5264D6C645DD1664B5538085A0.tplgfr38s_2?idArticle= LEGIARTI000026910138\&cidTexte=LEGITEXT000026910098\&dateTexte $=$ 20200728

Supplemental material This content has been supplied by the author(s). It has not been vetted by BMJ Publishing Group Limited (BMJ) and may not have been peer-reviewed. Any opinions or recommendations discussed are solely those of the author(s) and are not endorsed by BMJ. BMJ disclaims all liability and responsibility arising from any reliance placed on the content. Where the content includes any translated material, BMJ does not warrant the accuracy and reliability of the translations (including but not limited to local regulations, clinical guidelines, terminology, drug names and drug dosages), and is not responsible for any error and/or omissions arising from translation and adaptation or otherwise.

Open access This is an open access article distributed in accordance with the Creative Commons Attribution Non Commercial (CC BY-NC 4.0) license, which permits others to distribute, remix, adapt, build upon this work non-commercially, and license their derivative works on different terms, provided the original work is properly cited, appropriate credit is given, any changes made indicated, and the use is non-commercial. See: http://creativecommons.org/licenses/by-nc/4.0/.

\section{ORCID iD}

Mehdi Mejdoubi http://orcid.org/0000-0001-9422-9356

\section{REFERENCES}

1 Dong E, Du H, Gardner L. An interactive web-based dashboard to track COVID-19 in real time. Lancet Infect Dis 2020;20:533-4.

2 Salje H, Tran Kiem C, Lefrancq N, et al. Estimating the burden of SARS-CoV-2 in France. Science 2020;369:208-11.

3 Geodes.santé publique france. Daily in-hospital deaths in France by counties. Available: https://geodes.santepubliquefrance.fr/\#c= indicator\&i=covid_hospit_incid.incid_dc\&s=2020-04-06\&t=a01\& view=map2 [Accessed 10 Jun 2020].

4 INSEE. French population by County. Available: https://www.insee.fr/ fr/statistiques/1893198 [Accessed 10 Jun 2020].

5 Legifrance. French counties classified by a weather index. Available: https://www.legifrance.gouv.fr/affichTexteArticle.do;jsessionid= C15D8E5264D6C645DD1664B5538085A0.tplgfr38s_2?idArticle= LEGIARTI000026910138\&cidTexte=LEGITEXT000026910098\& dateTexte $=20200728$ [Accessed 10 Jun 2020].

6 Cummings MJ, Baldwin MR, Abrams D, et al. Epidemiology, clinical course, and outcomes of critically ill adults with COVID-19 in New York City: a prospective cohort study. Lancet 2020;395:1763-70. 
7 Zhou F, Yu T, Du R, et al. Clinical course and risk factors for mortality of adult inpatients with COVID-19 in Wuhan, China: a retrospective cohort study. Lancet 2020;395:1054-62.

8 Petrilli CM, Jones SA, Yang J, et al. Factors associated with hospital admission and critical illness among 5279 people with coronavirus disease 2019 in New York City: prospective cohort study. BMJ 2020;369:m1966.

9 Pareek M, Bangash MN, Pareek N, et al. Ethnicity and COVID-19: an urgent public health research priority. Lancet 2020;395:1421-2.

10 Ing AJ, Cocks C, Green JP. COVID-19: in the footsteps of Ernest Shackleton. Thorax 2020;75:693-4.

11 Mizumoto K, Kagaya K, Zarebski A, et al. Estimating the asymptomatic proportion of coronavirus disease 2019 (COVID-19) cases on board the diamond Princess cruise SHIP, Yokohama, Japan, 2020. Euro Surveill 2020;25:2000180.

12 Liu J, Zhou J, Yao J, et al. Impact of meteorological factors on the COVID-19 transmission: a multi-city study in China. Sci Total Environ 2020;726:138513

13 Russell TW, JT W, Clifford S. Centre for the mathematical modelling of infectious diseases COVID-19 Working Group. Effect of internationally imported cases on internal spread of COVID-19: a mathematical modelling study. Lancet Public Health 2020:S24682667(20)30263-2.

14 Walker A, Houwaart T, Wienemann T, et al. Genetic structure of SARS-CoV-2 reflects clonal superspreading and multiple independent introduction events, North-Rhine Westphalia, Germany, February and March 2020. Euro Surveill 2020;25:2000746

15 Shi $\mathrm{P}$, Dong $\mathrm{Y}$, Yan $\mathrm{H}$, et al. Impact of temperature on the dynamics of the COVID-19 outbreak in China. Sci Total Environ 2020;728:138890.
16 Qi H, Xiao S, Shi R, et al. COVID-19 transmission in mainland China is associated with temperature and humidity: a time-series analysis. Sci Total Environ 2020;728:138778.

17 Sajadi MM, Habibzadeh P, Vintzileos A, et al. Temperature, humidity, and latitude analysis to estimate potential spread and seasonality of coronavirus disease 2019 (COVID-19). JAMA Netw Open 2020;3:e2011834.

18 Mejdoubi M, Kyndt X, Djennaoui M. Icu admissions and in-hospital deaths linked to COVID-19 in the Paris region are correlated with previously observed ambient temperature. PLOS One 2020;15:e0242268.

19 Isaia G, Diémoz H, Maluta F, et al. Does solar ultraviolet radiation play a role in COVID-19 infection and deaths? an environmental ecological study in Italy. Sci Total Environ 2021;757:143757.

20 Zhang H-J, Su Y-Y, Xu S-L, et al. Asymptomatic and symptomatic SARS-CoV-2 infections in close contacts of COVID-19 patients: a seroepidemiological study. Clin Infect Dis 2020:ciaa771.

21 Prata DN, Rodrigues W, Bermejo PH. Temperature significantly changes COVID-19 transmission in (sub)tropical cities of Brazil. Sci Total Environ 2020;729:138862.

22 Hallal PC, Hartwig FP, Horta BL, et al. SARS-CoV-2 antibody prevalence in Brazil: results from two successive nationwide serological household surveys. Lancet Glob Health 2020;8:e1390-8.

23 Zoran MA, Savastru RS, Savastru DM, et al. Assessing the relationship between surface levels of PM2.5 and PM10 particulate matter impact on COVID-19 in Milan, Italy. Sci Total Environ 2020;738:139825.

24 Jüni P, Rothenbühler M, Bobos P, et al. Impact of climate and public health interventions on the COVID-19 pandemic: a prospective cohort study. CMAJ 2020;192:cmaj.200920 